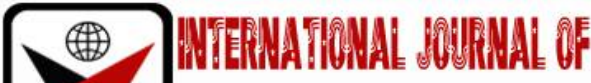

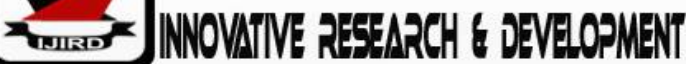

ISSN 2278 - 0211 (Online)

\section{Construction of Multipurpose Sieve Using Metallic Materials for Ceramic Industry}

\begin{tabular}{c}
\hline R. M. Gadzama \\
Associate Professor, Department of Industrial Design, \\
Modibbo Adama University of Technology, Yola, Nigeria \\
Obunna Emmanuel \\
Student, Department of Industrial Design, \\
Modibbo Adama University of Technology, Yola, Nigeria
\end{tabular}

\section{Abstract:}

This paper. focuses on the practical fabrication of multipurpose ceramics sieve (MPSC) machine, using locally available materials and tools. In the fabrication process, some tools such as drilling machine, file machine, hack saw, electric welding machine, metal pipes, bolts and nuts, improvised hack scissor were used in cutting, filling, welding and forging of some components that were assembled together using studio experimental method. The result of the concept of the multipurpose ceramics sieve machine was successful as shown in plate xiii. This prove that within immediate environment, materials could be sourced to solve studio problems such as sieving that is crucial as it helps in reducing the energy and time spent in manual clay and glaze processing in ceramics production.

Keywords: Multipurpose, sieve, metallic materials, ceramic industry

\section{Introduction}

The Ceramic section of Industrial Design is a section that uses a lot of tools and materials that help make the process of design easier. There is much more equipment that have found relevance in Ceramic design as they contribute to the overall finished work. The sieve is one such equipment that is used in the process of preparing clay, glaze, slurry or powdery material that is to be sifted. Sieve is used as separation equipment for removing unwanted particles like sand, stone, pieces of debris etc. from the clay in order to have clay, glaze of desired particle size. It can also be used to sieve glaze that is used in the coating of bisque ware for firing. Sieve is a very vital separation tool in conformity with the separation techniques of clay. It is equipment that works by allowing particles of different sizes to pass through the pores or aperture of a framed mesh.

Although, sieve is very important equipment which functions cannot be over emphasized in the ceramic section, little effort has been made in improving it from the common sieve that is obtainable, hence the need to improve on the common sieve that is used in most ceramic studios. The proposed multipurpose ceramic sieve (MPCS) will serve in multidimensional ways such as the interchangeability of mesh sizes, the duality in mechanism being manual and electrical by design, thus expected to make sieving work much easier. Furthermore, in being multipurpose in nature, it can serve for sieving clay, sieving glaze and other materials that involve separation technique.

Multipurpose ceramic sieve is an equipment with a framework across which is fastened an interwoven mesh or possibly a grid created by holes in a flat sheet of metal. A sieve also known as a screen is used to separate materials by size particles that will go through the holes and those that will not (source) Sieving can be done wet or dry. A screen used for materials in suspension in water is also called a sieve. A coarse screen which is made from interwoven wire and is used for dry material only is also called a riddle. The terms screen and screening imply a continuous process and are therefore more common in industry than in individual potter's workshop. However, the term screening or sieving is sometimes used by the individual potter to mean the use of middle -sized mesh between the fine sieve and coarse riddle. This would be between 40's and 10's mesh for wet or dry work but might include coarser meshes in wet work (Hamer, 1979) and it's very vital in ceramic processing.

MPCS is a kind of equipment fabricated to be used in separating solid particles. The sieving equipment works allowing solid particles of different sizes to pass through the pores or the aperture which can be interchangeable depending on the sizes and shapes. Basically, sieve equipment consists of a sieve preferably with the quality of shocker in accordance with its speed range.

\subsection{Statement of the Problem}

Despite the importance of sieve as basic equipment whose functions in ceramic processing cannot be over emphasized, little effort has been made in improving it from the common ones that have multi-faceted challenges such as 
slow and low output, wearing of hands while using it directly against the coarse mesh and unknown sharp objects that is hazardous to health, hectic in nature, time consuming associated with them. Instead of improving them by designing and constructing feasible ones by students of Department of Industrial Design in collaboration with the departments of Engineering being a University Technology that ought to do things machine-driven, there has been a gross dependence on imported sieves whose challenges include costly charges and are prone to damages during transportation. Therefore, this paper seeks to design and construct a multipurpose ceramic sieve (MPSC) to improve the student's potter clay and glaze preparation processes for maximum output.

\subsection{Aim and Objectives of the Paper} objectives:

The aim of this project is to design and construct a multipurpose sieve. This was achieved through the following

- Identify materials suitable for the design and construction of a multipurpose ceramic sieve

- Design the proposed Multi-purpose Sieve (MPS) through sketches.

- Collect and construct the MPS.

- Test the workability of the constructed multipurpose ceramic sieve.

\section{Materials and Methods}

The research design used for this paper beginning with the description of materials, equipment, facilities, techniques and procedures used in this research for the construction of a multipurpose ceramic sieve (MPCS) for the preparation of clay and glaze are herewith explained below:

\subsection{Research Design}

Experimental research design was used as its basically construction or fabrication project. According to Thompson as cited in Alvin (2014), fabrication is the act of construction, especially from components to completeness. All machines are built up to the part made of different materials and by various manufacturing processes. Some part is cast from metals; some are forged, while others are produced by machining on different kinds of machine tools. Casting and forging have to be machined before they acquire their proper shapes; exact dimensions and surface finish forged parts, whether they are to be machined or not are called forgings. Forging processes are extremely important in the machine building industry. However, forging and stumping is particularly widespread in the tractor automobile, agricultural machinery, ship building, locomotive building and other industries (Shikar, 1970).

\subsection{Materials and Methods}

The following materials were sourced locally for the component parts in the construction of MPCS:

- Water trough (Galvanized metal)

- Mesh

- Angle bar

\subsection{Parts Used for the Drive Mechanism}

- Shaft

- Bearings/bearing housing

- Electric cable

- Electric motor"'/2 or 1 (one) horse power

- Electric switch (four ways)

- Electric motor with regulator

- Fiber brush

\subsection{Water Trough and Drum Framework}

- Galvanized metal sheet

- Gauge "18" mild steel

\subsection{Bearing}

- Bearing housing

- Bearings

- Nuts and bolts

- Brushing

- Gallery for the mesh

- Tool and Equipment

\subsection{Tools and Equipment}

- Welding machine

- Lathe machine

- Hack saw or cutting torch

- Drilling machine with assorted metal cutting bits. 
- Hammer

- Center punch

- Box figure i - iv. These are to ensure the feasibility of components, materials, fabrication upon which a workable construction of MPSC.

- Transformation of drawing with computer in order to have the best of working drawing, the hand drawings were further refined with computer using Photoshop software. The drawings are done according to specifications.

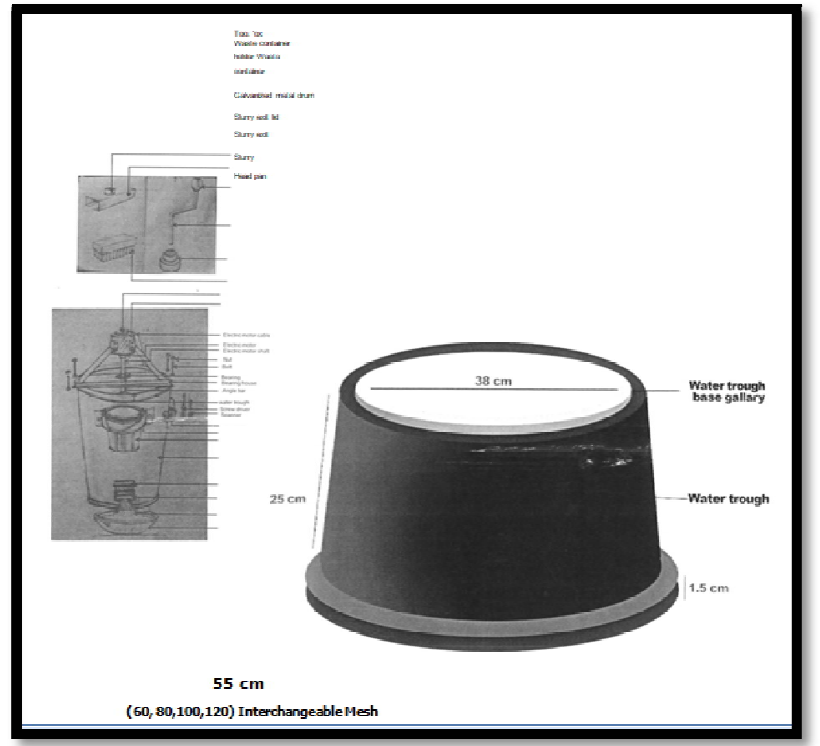

Figure 1

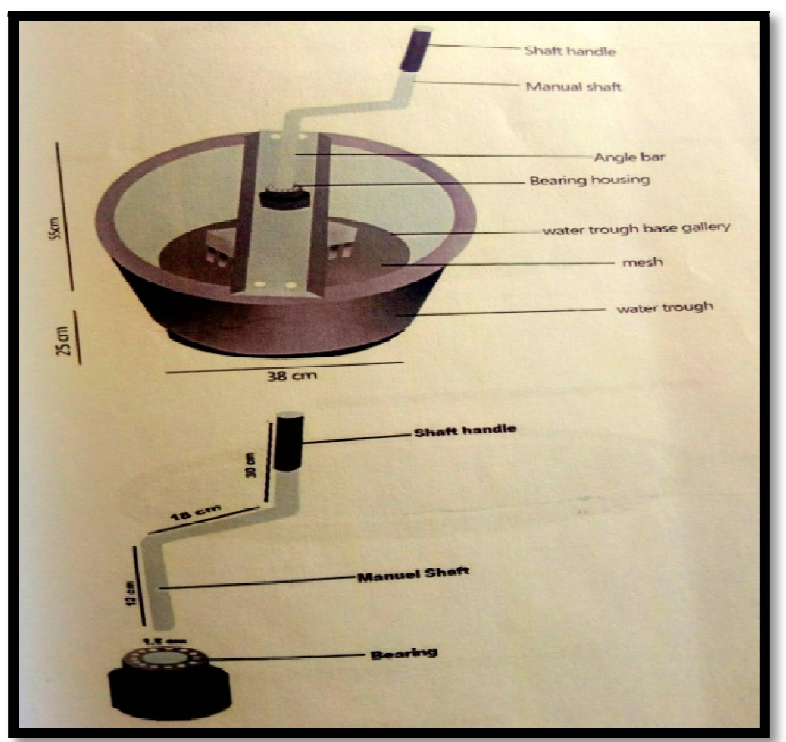

Figure 2: Parts of a Multipurpose Ceramic Sieve

\subsection{Identifying of Materials}

\subsubsection{Metals}

Metals are generally very strong and resistant to different kinds of corrosion. Though they are considerably of different varieties and strength, but in general, metals are marked by such properties as hardness, resistance to breakage, the ability to maintain original shape after deformation, and the ability to undergo deformation without breaking, (Needham, 1986:563).

In the process of fabrication of this multipurpose ceramic sieve, the following metals were considered: steel, Aluminum, galvanized sheet metal, Brass.

\subsubsection{Steel}

They are alloys of iron and carbon that is widely used in construction and other application because of their high tensile strengths. And that make it one of the most common materials in the world today used in building infrastructure, tools, ships, automobile, machines, appliances, and weapons (Glenn, 2009). Steel metal are used in the construction of roads, railways, appliances, and buildings. Steel is used in a variety of other construction materials, such as: bolts, nails, and screws and other household products and cooking utensils (Akanuma, 2005). 


\subsubsection{Aluminum}

It is a silvery white, soft and the second most widely used metal after iron. The structural components made from aluminum are so vital to the aerospace industry, and also important in other areas of construction and transportation. Despite its prevalence in the environment, aluminum is used for beverage cans, construction of windows, and doors, household items used for cooking utensils, electrical transmission lines for power distribution. The properties of aluminum include: low density, high strength, superior malleability, easy machining, excellent corrosion resistance and good thermal and electrical conductivity (Earnshaw, 1997).

\subsubsection{Galvanized Sheet Metal}

This has a unique metallurgical structure which gives outstanding resistance to the metals. The properties of galvanized steel are unique combination which can be used in interior and exterior application such as: car bodies, appliances, bolts/nuts, and roofs.

\subsection{Bolts and Nuts}

Bolts are cylindrical in shape with an integral head on one end, an external screw thread on the other end designed to be inserted through holes in assembling parts and to mate with an internally threaded block, called nuts that are turned to tighten or loosen the bolts. The fabrication of this machine is going to use bolts and nuts to tighten the parts together, using screw and spanner. Nuts are small metal block made in a variety of shape such as squares and hexagon to match a bolt.

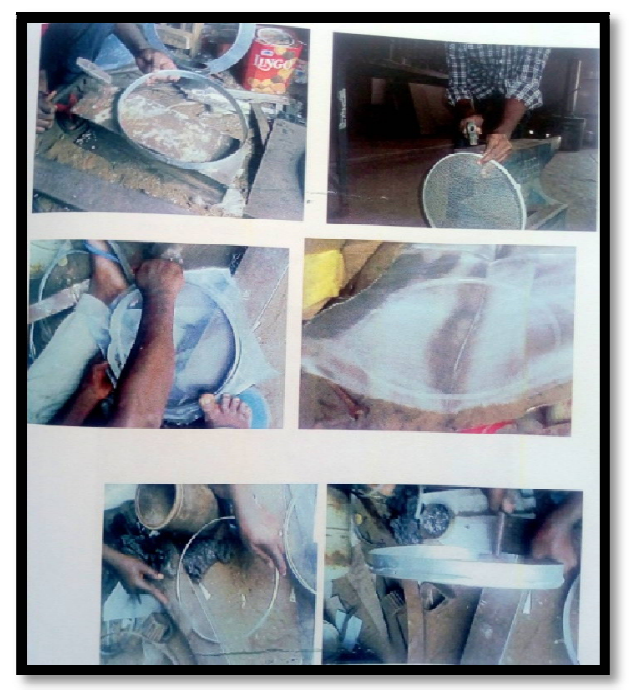

Figure 3: Cutting Forging and Manipulation of Mesh

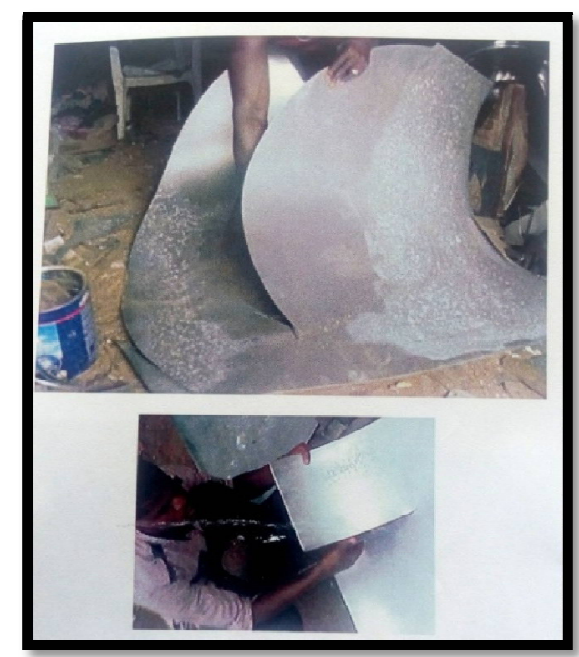

Figure 4: Cutting Galvanized Metal Sheet

\subsection{Construction Procedures}

\subsubsection{Cutting}

Galvanized metal sheet was cut according to the working drawings (see plates five). The sheet was cut into various parts needed to build the MPCS at the metal welder's shop. The cutting was done to specification of the required measurement using the acetylene gas, angle grinder, hack saw and a shearer (a scissors like tool for cutting metals). 


\subsubsection{Welding}

After the cutting of the sheet to various measurements of different components, welding stage was the next stage. The welding is done with a welding machine. It is done properly with to ensure that the whole construction lasts and does not disintegrate after a while.

\subsubsection{Assembling}

The assemblage stage was done gradually by coupling parts of each component; joining them to the appropriate side as pre-designed as seen in plate.... There are basically two forms of the assemblage, thus the welded ones that permanent and that ones that are flexible where the bolts and nuts that could loosen and tightened intermittently.

\subsubsection{Drilling}

After the aforesaid - cutting and welding, were done, the required holes for would be screwed with bolts and nuts were drilled. The drilling machine was used for this purpose as seen in plate xi.

\subsubsection{Finishing}

Next to the drilling is the finishing that involves filling of rough edges by with filler with angle and bench grinder and sandpapering with sandpaper for surface treatment such as smoothening in order to ensure that the equipment is friendly to work with.

\subsection{Fiber Brush}

Fiber brush of $30 \mathrm{~cm}$ with hard tip that can withstands quick wearing was manipulated to make easy rubbing on the mesh surface while sieving clay and/or glaze of fine particle size from unwanted particle through the sieve. The fiber brush with width of ...cm is good enough to determine the gallery base width, mesh sizes, workability as well as the size of the water trough.

\subsubsection{Fiber Brush Framework}

This framework involves constructing from mild steel that will agree to and easily fit in and removal of the wooden handle of the fiber brush. It is forged in such a way that the shaft can comfortably drive the fiber brush attached to the framework without the brush shifting, drifting/ pulling out from the framework while sifting. The framework is forged in a way that the fibre brush's handle can be easily removed for proper washing even after sifting is done, this framework's middle top has also a little fabrication to enable it to fit into the required shaft and is well tighten with a screw to be driven by either the manual or electric shaft.

\subsubsection{Water Trough}

The construction of the water trough began with obtaining the width of the brush tip which is $30 \mathrm{~cm}$, using the compass to determine the radius of the brush tip. Then an increase of $2 \mathrm{~cm}$ was done to the compass such that after the radius has been mapped out, it will I give the base of the galvanized sheet. The size of the water trough was cut out depending on the size of the base gallery of $34 \mathrm{~cm}$. A fulcrum shape was introduced from below to the top of the water trough having a height of $45 \mathrm{~cm}$ to maintain a tidy working space while sieving; the rim of $65 \mathrm{~cm}$ in diameter with an outer rim extension of $3 \mathrm{~cm}$. Perforations to introduce bolts and nuts to hold angle bar which carry the bearing/bearing house and to support the trough to remain comfortably on the rim of the drum were also introduced.

\subsubsection{Water Trough Base Gallery}

The base being essential as the water trough itself is intricate because a circular base forged gallery is to determine the interchangeable mesh width where the slip passes through, the mesh was forged to fit easily without forcing it from the base gallery of $34 \mathrm{~cm}$ width with the spinning of the fibre brush tip that is driven by either the manual shaft or the electric driven shaft.

Other parts like the shaft (drive) and the bearing housing compartment pass through the forgery as they were produced from solid thick rods of mild steel for the constructed parts are:

- $\quad$ Shaft (drive shaft)

- Bearing housing

\section{Results and Discussion}

\subsection{Results}

The outcome of constructed galvanized MPCS for the preparation of clay and glaze is explained herewith. The manual sieve handle that was fabricated using steel metal pipe of $1.5 \mathrm{~cm}$ thickness and a length of $60 \mathrm{~cm}$ was bent into two joints to obtain $30 \mathrm{~cm}, 18 \mathrm{~cm}$ and $12 \mathrm{~cm}$ respectively was successfully. For the electrical aspect of the sieve, motor drive has a fabricated supportive bar attached to support the motor by keeping it in suspension as seen in plate. The silver coated steel metal is $30 \mathrm{~cm}$ long that has two perforations for the screws to support the electric motor on suspension and for a steady spinning of the motor, $4.5 \mathrm{~cm}$ length of metal pipe with a thickness of $1 \mathrm{~cm}$, a drilled hole for bolt was fabricated for the electric motor shaft.

The bearing house bar of $60 \mathrm{~cm}$ length, with a width of $17 \mathrm{~cm}$, which was bend into four places to cut out location for the bearing house. The bearing house has $4.5 \mathrm{~cm}$ width a length of $2 \mathrm{~cm}$, the bearing of $2 \mathrm{~cm}$ diameter, a 
shaft of $15 \mathrm{~cm}$ height beneath the bearing house bar, the brush handle frame has a length of $32 \mathrm{~cm}$ height of $3 \mathrm{~cm}$, width of $7.5 \mathrm{~cm}$, a brush frame pipe shaft of $5 \mathrm{~cm}$ height, thickness of $1.5 \mathrm{~cm}$ with a fabricated screw hole.

The slip trough has a height of $25 \mathrm{~cm}$, a rim diameter of $55 \mathrm{~cm}$, outer rim flange of $3 \mathrm{~cm}$, an entire base of $38 \mathrm{~cm}$, the foot rim height of $1.5 \mathrm{~cm}$ with an inner width flange of $1 \mathrm{~cm}$.the galvanized metal mesh frame has a dimension of $32 \mathrm{~cm}$, height of $1.5 \mathrm{~cm}$, mesh also has different aperture sizes base on lower number meshes are coarser and are typically used for clays and slips. High number meshes are finer and used for glazes. The number (40, 60, 80, and 100) represents the number of wires in the mesh per linear inch. Slip drum has a height of $86 \mathrm{~cm}$, the rim and foot rim diameter are $55 \mathrm{~cm}$ respectively, the slip drum spout has a length $10 \mathrm{~cm}$, width $8 \mathrm{~cm}$, height $6 \mathrm{~cm}$, spout has a length $10 \mathrm{~cm}$, width $8 \mathrm{~cm}$, height $6 \mathrm{~cm}$, spout lid length of $1 \mathrm{lcm}$ and a width $8 \mathrm{~cm}$.

Waste bucket has height of $27 \mathrm{~cm}$, base of $19 \mathrm{~cm}$ diameter and a rim of $27 \mathrm{~cm}$, tool box has length of $18.5 \mathrm{~cm}$ and width of $15 \mathrm{~cm}$ as same as its lid. The researcher was able to advance his own sieve equipment innovation by fabricating a deeper slip trough, slip drum, its spout and lid, waste bucket and tool box alongside their hangers using only galvanized and steel metal.

The multifunctional or multipurpose sieve serve the same function like other sieve tool constructed with wooden frame, plastic frame and other materials. The purpose of this paper is to solve the challenges such as slow and low out output, wearing of hands while using it directly against the coarse mesh and unknown sharp object that is hazardous to health, hectic nature, time consuming associated with it and spillage of slip from slip trough during clay, glaze preparation. After the process of fabrication, the research was able to proffer solution to the sieving challenges. This research paper brought to reality different material, techniques and equipment that made the fabrication easy to achieve. For instance, the researcher was to utilize chisel to bore holes on the bearing house bar, flange for the slip drum and slip trough the manipulation seems to be unproductive, so the researcher deviated to more mechanized medium, using an industrial drilling machine and it made the drilling easy. After the whole design was conceived and deliberated on, the fabrication became reality due to the detailed drawings of project design and the manual and electric motor drive of the equipment was tested, and the right result was realized.

In testing the efficiency of the project, the researcher discovered that sieving process in clay preparation became fast and yield high output, less or no energy was required, the less use of hand while sieving unlike the previous challenges experienced during sieving.

\subsubsection{The Plates Below Show the Fabrication Processes}

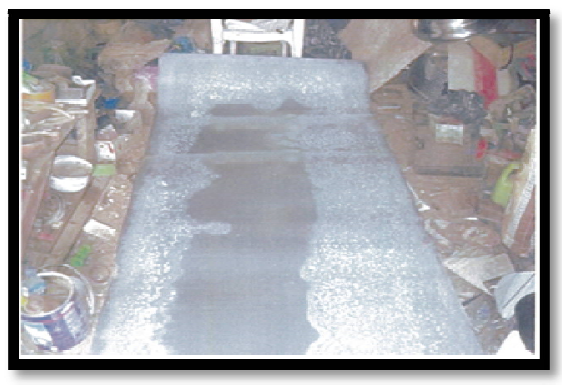

Figure 5

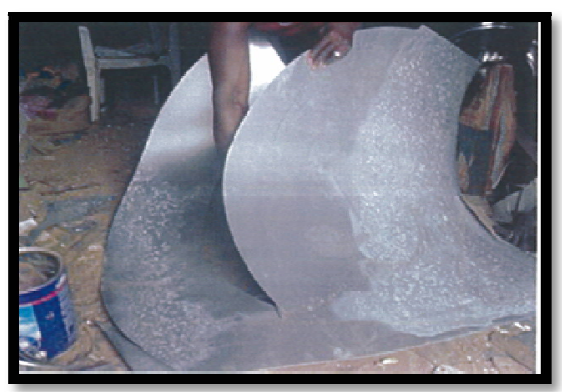

Figure 6 


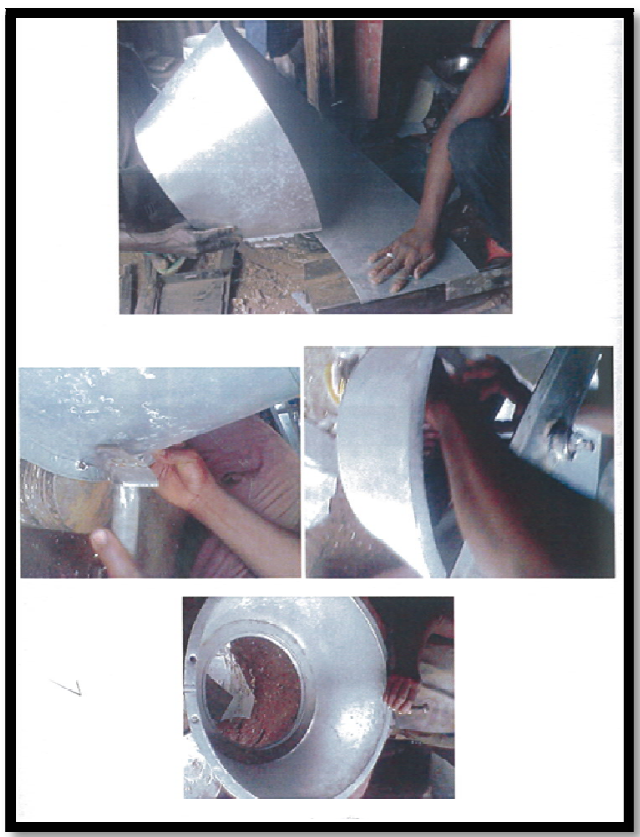

Figure 7: Cutting, Forging and Manipulation of Slip through Flange for Mesh

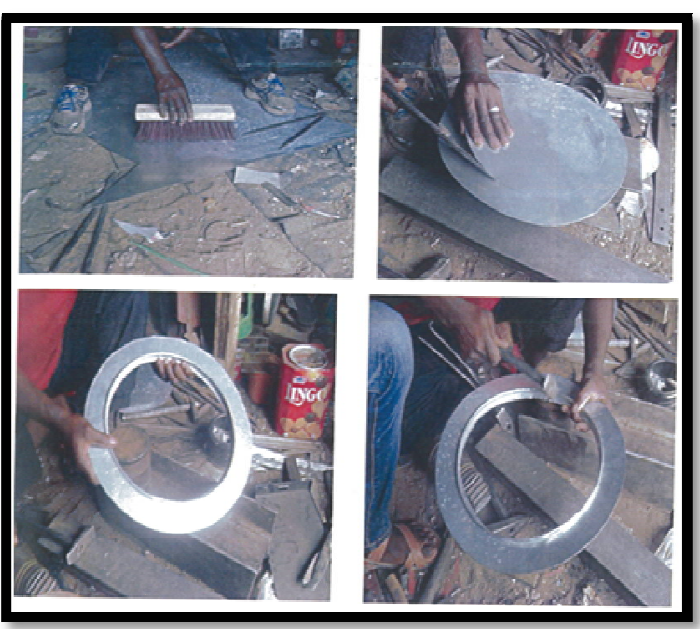

Figure 8

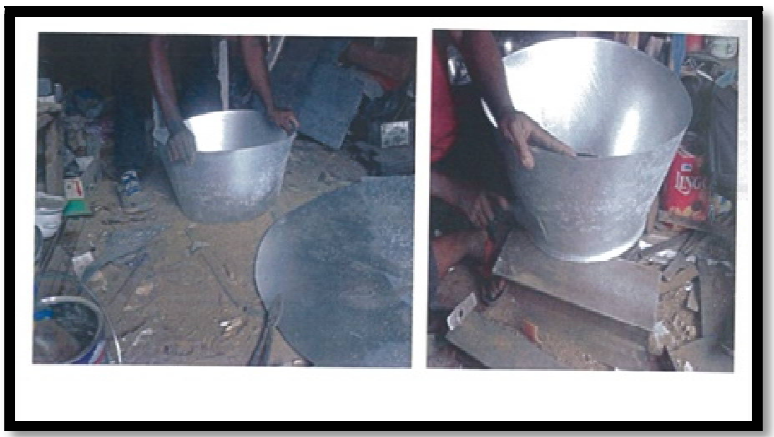

Figure 9: Cutting, Forging and Manipulation of Slip through Flange for Mesh 


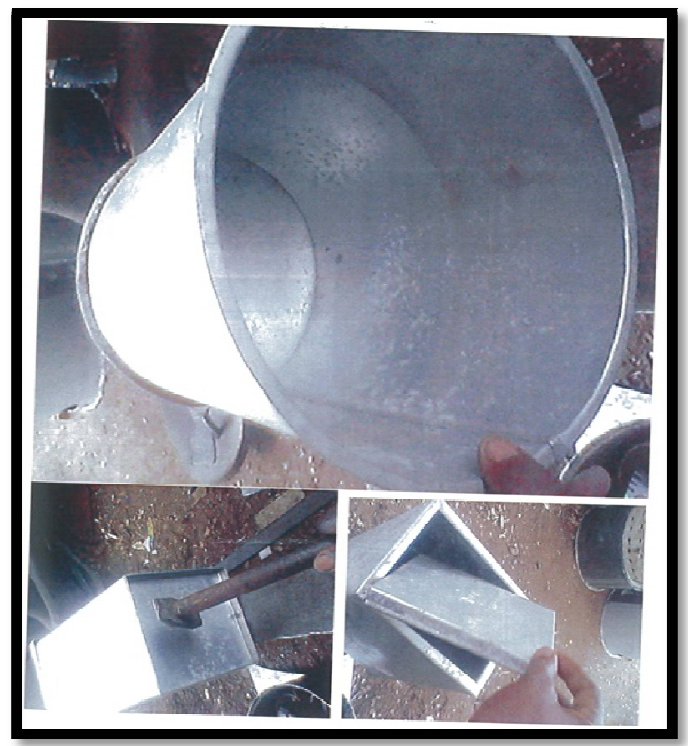

Figure 10

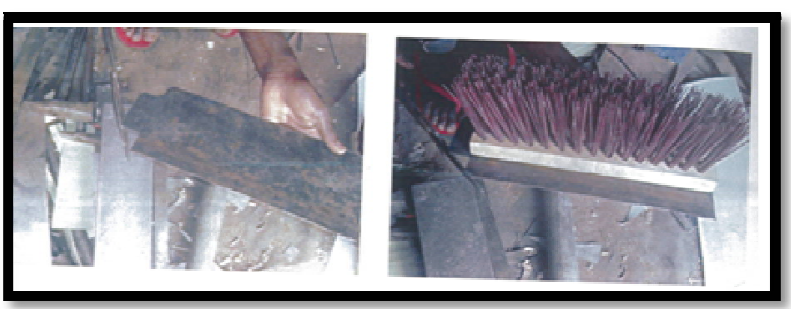

Figure 11: Cutting and Blending of Brush Handle Framework

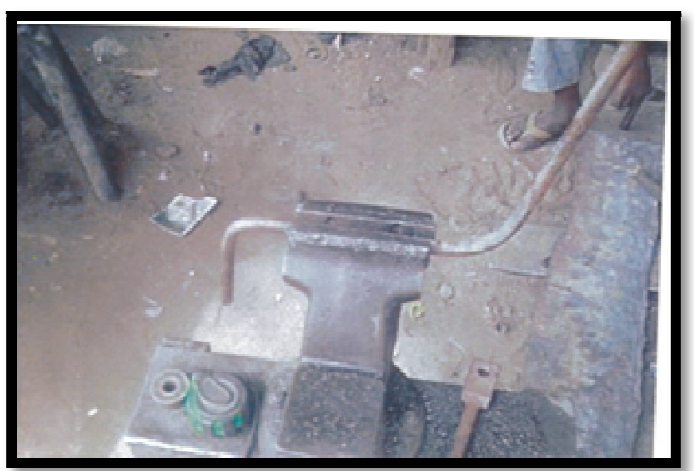

Figure 12: Cutting and Bending of Manual Handle Driver

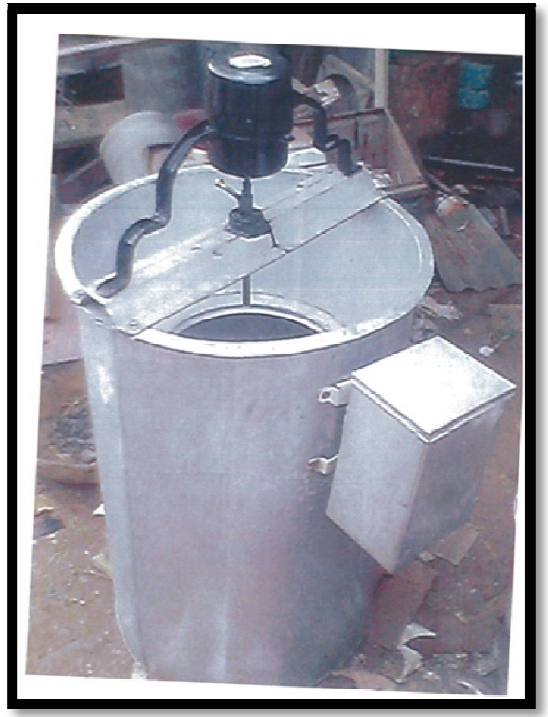

Figure 13 


\subsection{Final Process}

Creating curve shapes on the bearing house of the flat bar which will allow the bearing to comfortably in its house without shifting or wobbling, the tool used was the chisel which has end, so it requires carefulness to achieve the accurate dimension which can fitly modulate the bearing, in attempting to use this aforementioned approach the improvise $\mathrm{d}$ did not trivial, so the researcher result to the use of an electric file machine which finally $r$ solution to the problem. The four supportive bars to the electric motor were also out by machine instead of the inadequate chisel tool. The brush handle frame also involves the use of file machine to cut a flat bar, the flat bar merely $40 \mathrm{~cm}$ length and $15 \mathrm{~cm}$ width before the use of file machine to cut four angle of the $r$ and then use bending machine to create bent that would accommodate the brush handle. ii it was a huge challenge in achieving the brush handle frame, the use of the file machine and bend machine to achieve curve shape made the fabrication achievable. The slip drum made its lid cover also include cutting and bending, since they all involve the use of sized metal which could be easily cut using an improvised hack scissor, there was no need a file machine, but the problem encountered was forging the spout and cutting out a dimension of lid cover that would fit perfectly to the flange of the spout without facing difficulty when opening and closing spout after fabrication. Waste bucket and tool box hangers, because of their curve shapes in creating this the her had difficult experience in using saw to cut out, but with the use of file machine and machine, cutting and bending became easy.

Slip drum and trough, bearing house bar, electric motor supportive bar, manual drive That $\mathrm{p}$ rod and a hammer which requires carefulness to achieve the accurate dimension owing to fact that the nuts and bolts, must fit tightly and firmly to avoid wearing and tire. Using this excess it made drilling of neat perforated holes on component difficult, so the researcher; tilted to using the drilling machine which finally solved the problem of neat drilling and perceiving precise dimension.

\subsubsection{Welding the Metal}

Components like electric motor supportive bar, bearing house, shaft, the shaft house on brush handle frame work, shaft housing attached to the electric motor shaft all required ding. The challenge involved in the process is that fabrication requires a lot of power supply, to machines that demands high voltage. As a result of low power supply from NEPA, the publication was not efficient enough so the research has to spend extra capital to fuel the ${ }^{\circ}$ rator to accomplish the work in time.

\subsubsection{Assembly}

In component assemblage, since there are a lot of perforation on the parts and the use of and nuts, a user must carefully note various components and stages of both the manual and component in order not to displace or misplace the assemblage of various components of equipment. Make sure you observe the design detail and parts are well assembled without is any part behind.

\subsubsection{Finding}

In procedure of fabrication of this manual and electrical sieve the researcher found that not every metal can be used in fabrication of an electric and manual sieve. Metals like stainless, aluminum, tin, tend to be too light for fabrication especially forging the mesh framework, slip through foot rim gallery.

The result of this research shows that the galvanized metal tends to be a material that could best serve for the fabrication of an electric and manual sieve because of its high resistance to rust and good duration of life spam to withstand corrosion in clay and glaze preparation.

The result of this paper shows that the interchangeable sieve gives an advantage of using on sieving equipment to sieve different slip particles size base on mesh aperture to yield desire result. The use of the manual and electric motor which drives the shaft to the use of bear hands directly on the coarse mesh. It also helps in mass glaze or clay preparation. The researcher sourced local materials from scraps market and realized that scraps are compactible to be used in the fabrication of electric and manual sieving equipment.

\section{Summary, Conclusion and Recommendation}

\subsection{Summary}

This project, design and construction of an electric and manual sieve machine using label materials around the environment such as; galvanized metal sheet, steel metal sheet, , drilling machine, electric welding machine, file machine, flat bar, bearing, electric motor, 1 and other components that are suitable for fabrication of an electric and manual sieve line. The various components were assembled together to produce a complete sieve line.

\subsection{Conclusion}

An outcome of this paper electric and manual sieve machine was successfully gated with the use of locally sourced materials from Jimeta/Yola such as Jambutu Bye-pass. Machine can serve the same function like other sieve, and can also compete and be compared with the foreign types. However, at the end of this work, it was discovered that locally ed materials such as; an improvised hack scissor, steel metal, hand file, file machine, hand $\mathrm{T}$, sand paper, paints, brush, bolts and nuts, window mesh size (net), can serve to element in fabricating an electric and manual sieve machine.

With the use of these local materials alongside galvanized metal, the researcher was able fabricate a manual and electric sieve that can be utilized in clay and glaze preparation of different particles size based on mesh apertures sizes which can be used in the department of industrial design (MAUTECH Yola). 


\subsection{Recommendations}

Proper safety protection measures should be adhered to during fabrication procedures. For instance, the need to wear safety hand gloves and eye glass, endrums protector to avoid the hazardous effect of sparks, dangerous ultra-violet and infrared rays, iron, fillings and foreign particles from being in halted during cutting, welding, bending and drilling activities are ongoing

Further research should be carried out to advance this project such designing it to an automatic multipurpose sieve machine which can plunge as well as sieve clay or glaze. Since the university is technologically inclined in nature student should be encouraged to undertake more design drawing and project on fabrication than theory.

The paper also recommended that the department of industrial design should include on its curriculum an effect implementation of the use of up cycling materials in meeting low cost implication project that are technologically driven there by proffering solution to the immediate needs and problems in the department.

Government should provide project materials on subsidize rate to argument financing of student project and to also employee capable hands who has in depth technical know-how in interpretation of design drawing and fabrication, this goes a long way of improving technology development in tertiary institution.

\section{References}

i. A project Report of Construction of industrial sieve compartment---www.google.com retrieved 15 $5^{\text {th }}$ March 2016.

ii. Akannume, H, (2005) "the significance of the composition of excavated iron fragments taken stratum III at the site of Kaman-Kalehoyuk, Turkey. Anatolian Archaeological studies. 14:147-158.

iii. Bromwell (2012). Test sives for laboratories- Retsch Test Soeve- restsch.com

iv. Chinois-www.wikipedia.com Retrieved 17th March 2016.

v. Cocktail strainer-www.about.com. Retrieved 15th March 2016

vi. Colander-www.ask.com. Retrieved 15th March 2016.

vii. Dakyes, S.U (2013) the Role of an industrial designer in Local product development in a developing economy, journal of Arts and idea. IIe-Ife, Vol pp 218, 220

viii. Design and fabricate slieve machine-MOHD EFFI B MOHJEE- A project report submitted in partial fulfillment of the Requirement for the award of the Diploma of mechanical Engineering

ix. Elert, Glenn (2009) Density of steel, retrieved 23 March 2016

x. Federal university of Technology, Akure, pp. 8-13 National policy of Education (1988) NERDC press, Yaba, Lagos, Nigeria Revised Edition.

xi. Greenwood N.N., and A. Earnshaw, 1998 Chemistry of the Elements, $2^{\text {nd }}$ ed, Oxford, U.K; Burlington, MA; Butterworth- Heinemann, Elservier science.

xii. Harvey R. and Sylvia and kolb J. (1998) Building Pottery Equipment. Waston Guptill

xiii. Illustrated oxford Directory (1998): Dorling Kindersley Limited and Oxford University press.

xiv. Needham, N.G (1986) fundamental of creep in metals and Alloys, pp. 563.

xv. Salau, A.M. (2005) shaft of Distinctions: An Anatomy of Achievements in Techno-Artistics (Shikar, 1970).

xvi. Sieve- www.wisegeek,com. Retrieved 17th March 2016.

xvii. Sieve- www. Wisegeek, com. Retrieved 17th March 2016. 